\title{
Türkiye Kira Sertifikalarının Konvansiyonel Piyasalarla Uzun Ve Kısa Dönemli İlişkisi*
}

\author{
Berkan ATAŞ** \\ Ali HEPŞEN ${ }^{* * *}$
}

\section{ÖZET}

Çalışmada Türkiye sermaye piyasalarına dahil edilen yeni bir ürün olan kira sertifikalarl, veya uluslararası bilinen ismiyle sukuk, piyasalarının ulusal ve uluslararası konvansiyonel yatırım araçları olan hisse senedi ve tahvil piyasaları ile uzun ve kısa dönemli ilişkisi ölçülmektedir. Çalışmanın temel amacı kira sertifikaları piyasasının konvansiyonel yatırımcılar tarafından da çeşitlendirme bakımından kullanılabilirliğinin araştırılmasıdır. Uzun dönemli ilişkinin testi için Johansen koentegrasyon analizi kullanılmıştır. Bunun yanında varyans ayrıştırması yöntemi kullanılarak kira sertifikalarında meydana gelen dalgalanmaların ne kadarının diğer piyasalardaki dalgalanmalar tarafından açıklandığı incelenmiştir. Çalışmanın sonuçlarına göre Türkiye kira sertifikalart piyasası hem ulusal hem de uluslararası konvansiyonel yatırım araçları için yatırım çeşitlendirmesi açısından faydalıdır.

Anahtar Kelimeler: Kira Sertifikaları, Çeşitlendirme, Koentegrasyon, Varyans Ayrıştırma.

JEL Sınıflandırması: F36, G11, G15

\section{The Long And Short Term Comovement Between Turkish Lease Certificate Market} And Conventional Markets

\section{ABSTRACT}

Lease certificate or the common global name sukuk, has been recently introduced to Turkish financial market. Indubitably, new financial service or security is quite beneficial in terms of market depth and adequacy. In this paper, we investigate the long and short term comovement between Turkish lease certificate market and national or international conventional bond and stock market. Our purpose is to examine this market with regard to diversification benefits for conventional investors point of view. To investigate long term comovement we employ the Johansen cointegration test. Besides, for short term relationship, we employ the variance decomposition test. We observe that, Turkish lease certificate market is favourable for national and international diversification.

Keywords: Lease Certificate, Diversification, Cointegration, Variance Decomposition

Jel Classification: F36, G11, G15

\footnotetext{
* Makale Gönderim Tarihi: 09.06. 2020, Makale Kabul Tarihi: 29.09.2020, Makale Türü: Nicel Araştırma

** Ar.Gör.Dr., İstanbul Üniversitesi, İşletme Fakültesi, atasberkan@gmail.com, ORCID: 0000-0003-3049-3195.

*** Prof.Dr., İstanbul Üniversitesi, İşletme Fakültesi, ali.hepsen@istanbul.edu.tr, ORCID:0000-0002-3379-7090.
} 


\section{GİRIŞ}

2011 yılının sonlarında yapılan kanuni düzenlemelerle ilk kez kira sertifikaları bir finansal enstrüman olarak sermaye piyasalarımıza kazandırılmıştır. Kira sertifikaları tüm dünyada sukuk olarak bilinen islami tahvillerin özel bir türüdür. İlk olarak Doğu Asya ülkelerinde 1970'li yıllarda gelişim gösteren faizsiz finansal ürünlerin günümüzde tüm dünya piyasalarında önemli derecede entegrasyon sağladığı görülmektedir. Günümüzde islami finansal ürünler sadece Müslüman ülkelerle sınırlı kalmayıp ABD, İngiltere, Kanada gibi gelişmiş ülkelerin piyasalarında da ihraç edilmekte ve ikincil piyasalarında işlem görmektedir (Yakar vd.,2013:73).

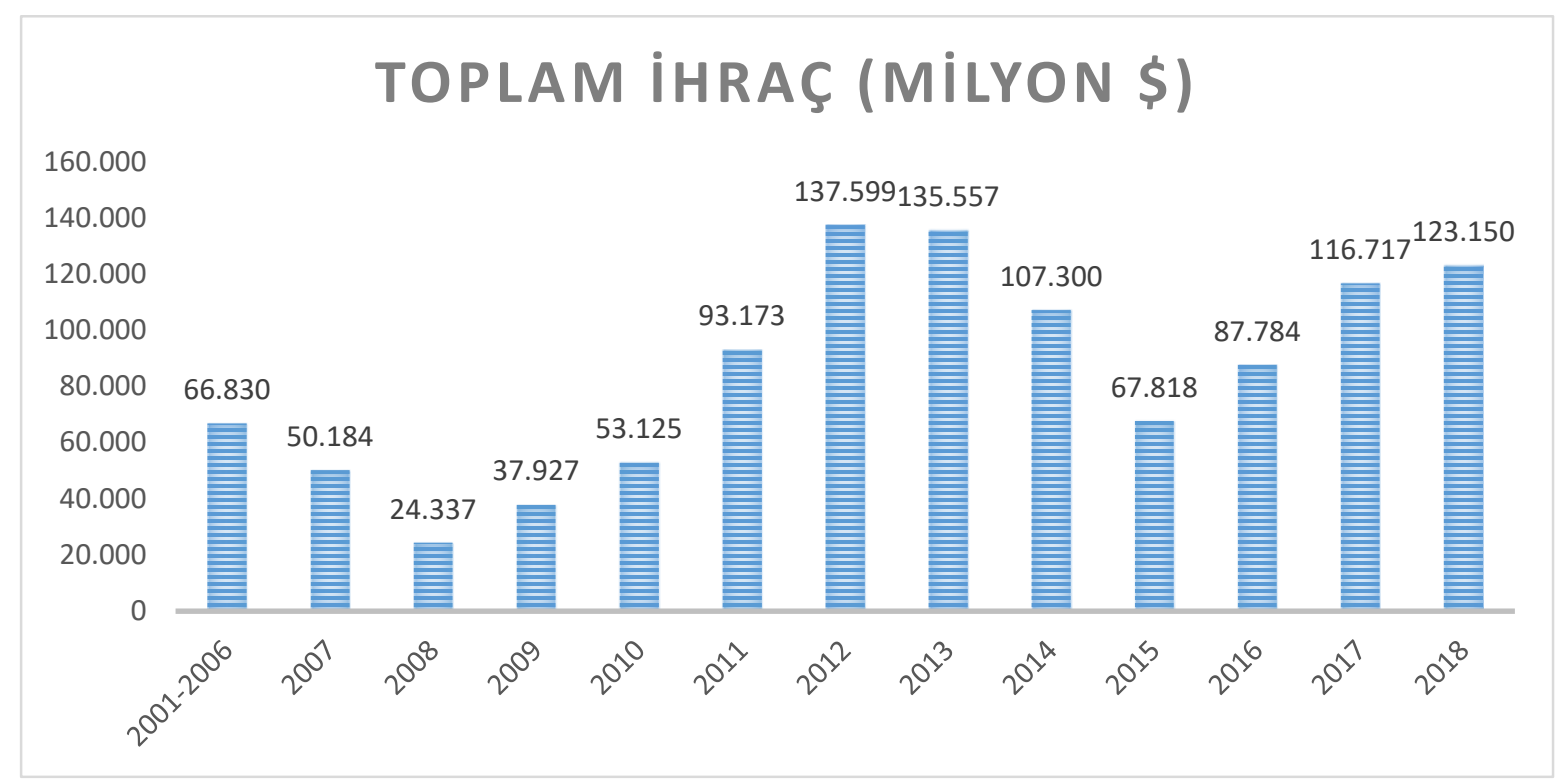

Kaynak: International Islamic Financial Market (IIFM) Temmuz 2019 raporu s.21

Grafik 1: Uluslararası Sukuk İhraçları

Yukarıdaki şekilde tüm dünyada ihraç edilmiş olan sukukların ABD Doları cinsinden toplam büyüklükleri yıllar itibariyle verilmiştir. 2018 yılında toplam sukuk ihraçları bir önceki yıla göre yaklaşık \%6'lık bir artış göstererek yaklaşık 123 Milyar Dolar seviyesinde gerçekleşmiştir. Grafikten global sukuk ihraç büyüklüklerinin yıllar itibariyle dalgalı bir seyir izlediği anlaşılmaktadır. Piyasanın, günümüzdeki büyüklükler göz önünde alındığında, 2000'li yıllara oranla oldukça büyük bir gelişim gösterdiği gözlemlenmekle birlikte, 2007 yılında ilk olarak ABD'de ortaya çıkan ve daha sonrasında yayılarak tüm dünya piyasalarını önemli ölçüde etkileyen küresel finansal krizden büyük ölçüde etkilendiği gözlemlenmektedir. Dalgalı yapısına rağmen giderek büyüyen bir trende sahip bir şekilde ihraç büyüklüklerinin arttığı görülmektedir. Nitekim Moody’s tahminlerine göre 2019 yılında toplam uluslararası ihraç büyüklügünün 130 milyar ABD Dolarının üstünde olması beklenmektedir (Moody’s, 2019:2).

Diğer yandan sukuk önceleri lokal olarak birkaç müslüman ülke tarafindan ihraç edilirken günümüzde, finans merkezi olma konusunda birbiri ile yarışan gelişmiş ve 
gelişmekte olan doğu ve batı ülkelerinin de ilgi gösterdiği finansal araçlardan biri olmuştur. Son yıllarda Hong Kong, Singapur, İngiltere ve ABD gibi finans merkezlerinin de bu piyasaya artan ilgisi söz konusudur. Aşağıdaki tabloda ülkelerin 2001-2018 yılları arasında sukuk ihraç büyüklükleri verilmiştir. Tabloda göze çarpan en önemli unsurlardan biri sukuk ihraçlarının sadece birkaç ülkeyle sınırlı olmaması Amerika kıtasından Afrika'ya kadar geniş bir yelpazedeki ülkeler tarafından ihraç edilmiş olmasıdır. Hiç şüphesiz bu piyasaların ileriki dönemlerde büyümesi ve bilinirliliğinin artması ile daha fazla global yatırımcıların ilgisini çekmesi mümkün olacaktır.

Tablo 1. Ülke Bazında Uluslararası Sukuk İhraçları

\begin{tabular}{|c|c|c|c|}
\hline \multicolumn{4}{|c|}{ Uluslararası Sukuk İhraçları Ocak 2001-Aralık 2018} \\
\hline Asya ve Uzak Doğu & Toplam İhraç (Adet) & Değer (Milyon \$) & \% Toplam Değer \\
\hline Çin & 1 & 97 & $0,04 \%$ \\
\hline Hong Kong & 4 & 3.196 & $1,27 \%$ \\
\hline Endonezya & 18 & 16.603 & $6,60 \%$ \\
\hline Japonya & 3 & 190 & $0,08 \%$ \\
\hline Malezya & 107 & 63.653 & $25,32 \%$ \\
\hline Pakistan & 4 & 3.600 & $1,43 \%$ \\
\hline Singapur & 4 & 711 & $0,28 \%$ \\
\hline Toplam & 142 & $\mathbf{8 8 . 0 5 0}$ & $35,02 \%$ \\
\hline Orta Doğu & Toplam İhraç (Adet) & Değer (Milyon \$) & \% Toplam Değer \\
\hline Bahreyn & 102 & 11.430 & $4,55 \%$ \\
\hline Kuveyt & 17 & 3.327 & $1,32 \%$ \\
\hline Umman & 5 & 4.219 & $1,68 \%$ \\
\hline Katar & 18 & 11.845 & $4,71 \%$ \\
\hline Suudi Arabistan & 59 & 47.324 & $18,82 \%$ \\
\hline Birleşik Arap Emirlikleri & 109 & 71.054 & $28,26 \%$ \\
\hline Toplam & 310 & 149.199 & $59,34 \%$ \\
\hline Afrika & Toplam İhraç (Adet) & Değer (Milyon \$) & \% Toplam Değer \\
\hline Nijerya & 1 & 150 & $0,06 \%$ \\
\hline Güney Afrika & 1 & 500 & $0,20 \%$ \\
\hline Sudan & 1 & 130 & $0,05 \%$ \\
\hline Toplam & 3 & 780 & $0,31 \%$ \\
\hline Avrupa ve Diğer & Toplam İhraç (Adet) & Değer (Milyon \$) & \% Toplam Değer \\
\hline Fransa & 1 & 1 & $0,00 \%$ \\
\hline Almanya & 3 & 206 & $0,08 \%$ \\
\hline Lüksemburg & 3 & 280 & $0,11 \%$ \\
\hline Türkiye & 24 & 9.762 & $3,88 \%$ \\
\hline Birleşik Krallık & 10 & 1.719 & $0,68 \%$ \\
\hline $\mathrm{ABD}$ & 5 & 1.367 & $0,54 \%$ \\
\hline Kazakistan & 1 & 77 & $0,03 \%$ \\
\hline Toplam & 47 & 13 & $5,33 \%$ \\
\hline Genel Toplam & 502 & 251.441 & $100 \%$ \\
\hline
\end{tabular}

Kaynak: IIFM, 2019 Temmuz raporu, s.27 
Yukarıdaki tabloda dikkat çeken durumlardan bir diğeri ise uluslararası ihraçların yaklaşık \%60'ının körfez ülkeleri tarafından yapılmasıdır. Körfez ülkeleri özellikle yeraltı zenginlikleri turizm ve taşımacılık gibi yüksek katma değerli alanlardaki etkinlikleri sayesinde son birkaç on yılda önemli bir sermaye birikimi elde etmişlerdir. Avrupa ve Asya'daki büyük sanayi ülkeleri petrol ihtiyaçlarını büyük ölçüde körfez ülkelerinden karşılamaktadırlar. Son dönemlerde sukuk piyasalarının tüm dünyada bilinirliğinin artmasındaki en önemli nedenlerden birisi de artan petrol fiyatları sonucu refah kazanan ve büyük sermaye birikimleri yaratan körfez ülkeleri yatırımcıları tarafından cazip ürünler meydana getirme çabalarıdır. Enerji piyasalarının giderek daha stratejik bir hale geldiği günümüz ekonomik koşullarından elbette sukuk piyasalarının da pozitif bir şekilde etkilenmesi kaçınılmaz olacaktır.

Sukuk piyasalarının giderek önem ve büyüklük kazanması ile birlikte bu piyasaların konvansiyonel varlık piyasaları ile ilişkisi merak uyandıran bir durumdur. Çalışmamızda Türkiye'de henüz yeni kurulan Kira Sertifikaları piyasasının hem ulusal hem de uluslararası hisse senedi ve tahvil piyasası ile uzun ve kısa dönemli ilişkisi incelenecektir. Uzun dönemli ilişkinin ölçümü için Johansen koentegrasyon analizi kullanılmıştır. Koentegrasyon analizi değişkenlerin uzun dönemde beraber hareketliliğini saptayan istatistiksel bir yöntemdir. Uzun dönemli ilişki ayrıca herhangi bir finansal varlığın diğer finansal varlıklar açısından çeşitlendirme faydası sağlayıp sağlamadığı hakkında da çıkarsama yapmamıza olanak sağlamaktadır. Eğer finansal varlıklar koentegre ise, piyasadaki bilgilere benzer davranışlar sergiledikleri için, bunları bir araya getirerek optimum derecede çeşitlendirilmiş portföyler meydana getirmek olası değildir. Diğer taraftan eğer finansal varlıklar koentegre değilse bu durumda bu varlıkların portföy yönetimi açısından bir araya getirilmesi durumunda çeşitlendirme optimizasyonu sağlanması mümkündür (Vo, Daly, 2005:156). Uzun dönemde ilişkinin varlığı aslında iki varlık arasındaki ilişkinin güvenilirliği hakkında çıkarsama yapmaya yaramaktadır. Kısa dönemde ilişkili gibi görünen varlıklar uzun dönemde birbirlerinden bağımsız şekilde seyredebilir. Bunun bir nedeni kısa dönemli ilişkinin tesadüfi olarak gerçekleşmesi olabilir (Sullivan, 2002:4). Ayrıca değişkenlere varyans ayrıştırma analizi uygulanarak uzun dönemli ilişkinin yanında kısa dönemli ilişkide ölçülmüştür. Elde edilen sonuçlara göre uzun dönemde kira sertifikaları piyasası diğer ölçülen ulusal ve uluslararası piyasalarla koentegre değildir. Kısa dönemde ise önemli derecede kendi iç şoklarından ve ulusal ve uluslararası tahvil piyasalarında meydana gelen dalgalanmalardan etkilenirken ulusal ve uluslararası hisse senedi piyasalarındaki dalgalanmalardan etkilenmediği görülmüştür.

\section{LITERATÜR}

Yatırım çeşitlendirmesi bir finansal piyasada tek bir varlığa yatırım yapmak yerine, riski minimize etmek amacıyla, birden fazla varlığa yatırım yapmak anlamında kullanılmaktadır. Her bir farklı varlığın benzer riskleri olabileceği (systematic risk) gibi kendine özgü riskleri (idiosyncratic risk) de bulunmaktadır. Çeşitlendirme yolu ile yatırımcılar, aynı bilgiye farklı şekilde reaksiyon gösteren varlıkları bir araya getirerek yatırım yaptıkları varlıkların kendilerine özgü risklerinden tamamen kurtulma şansını yakalarlar. Böylece getiriyi bir noktada sabit tutarken riski minimize ederek risk getiri optimizasyonu sağlanmış olur. $\mathrm{Bu}$ optimizasyon Markowitz'in modern portföy teorisinin temellerini oluşturmaktadır. Harry Markowitz, (Markowitz, 1952) ve (Markowitz, 1959) çalışmalarıyla modern portföy teorisinin kurucusu olarak tanınmaktadır. Markowitz'den 
önceleri de yatırım çeşitlendirmesinin faydaları bilinirken Markowitz'in bunu matematiksel olarak modellemesi finans literatürüne yepyeni bir boyut kazandırmıştır.

Markowitze göre $\mathrm{N}$ bir piyasadaki toplam yatırım yapılabilir varlık adedini göstermek üzere o piyasadaki $\mathrm{N}>1$ olması durumunda, başka bir deyişle eğer bir piyasada yatırım yapılabilir varlık adedi 1 'den fazla ise bu durumda sonsuz sayıda farklı yatırım bileşimi söz konusu olacaktır. Fakat bu farklı bileşimlerin hepsi etkin yatırımlar değildir. Rasyonel yatırımcı piyasada sonsuz yatırım bileşimi içerisinden sadece etkin olan yatırımları tercih edecektir. Etkin olan yatırımlar ise veri risk düzeyinde en yüksek getiriyi sağlayan yatırımların oluşturduğu sınırdır. Bu sınıra etkin sınır adı verilmektedir. Risk ve getiri diyagramı üzerinde etkin sınır altındaki herhangi bir yatırım alternatifi rasyonel yatırımcılar tarafından tercih edilmeyecektir (Yiğiter, Akkaynak, 2017:287).

Markowitz 1952-1959 yıllarındaki yaptığı çalışmalarla geliştirmiş olduğu risk-getiri temelli kuramla modern portföy teorisinin temellerini atmıştır (Yiğiter, Akkaynak, 2017:288). Varlıkların risk ve getirilerini baz alan teori için temel amaç risk getiri optimizasyonudur. Teori varlık serilerinin mükemmel derecede uyumlu hareket etmediklerini varsaymaktadır. Aynı bilgiye farklı tepkiler gösteren varlıklar nedeniyle risk bir noktaya kadar indirgenebilmektedir (Okuyan, Deniz, 2017:74).

İlk olarak Markowitz'le başlayan modern portföy teorisi farklı varlıklara yatırım yaparak riski dağıtma düşüncesini temel prensip haline getirmiştir. Bunun yanında yatırımcılar sadece kendi ülkelerindeki varlılar yerine uluslararası varlıklara da yatırımlarını gerçekleştirerek yatırım havuzunu zenginleştirip daha optimize portföylere sahip olabilirler (Omet, 2015:187). Uluslararası çeşitlendirme yolu ile sadece yerel varlıklarla oluşturulan portföylerden daha optimize portföylere yatırım imkanı ortaya çıkacaktır.

Sistematik riskler (faiz, enflasyon, döviz kuru gibi) bir ülkedeki tüm varlıkları etkisi altına alan risklerdir. Modern portföy teorisine göre sistematik risklerden çeşitlendirme yolu ile kaçınmak mümkün değildir. Fakat uluslararası çeşitlendirme yolu ile, sistematik risklerden de kısmen kaçınmak mümkün bir hale gelmektedir. Örneğin Çin piyasasında makroekonomik verilerle ilgili meydana gelen bir dalgalanma Arjantin piyasasını ya çok sınırlı veya hiç etkilemeyecektir. Bu nedenle farklı ülkelerdeki piyasalar aynı sistematik etkiye farklı tepkiler verdikleri için sistematik riskten kaçınma olanağı da kısmen mümkün hale gelecektir (Okuyan, Deniz, 2017:76).

1960'lardan sonra uluslararası sermaye akımlarına yönelik deregülasyonlar neticesinde uluslararası çeşitlendirme kavramı literatüre girmeye başlamıştır. Günümüzde bir çok ülke uluslararası sermaye hareketlerini kısmen veya tamamen serbest bırakmıştır. Bu sayede denizaşırı ülkelerde yatırımlar oldukça kolaylaşmıştır. Serbest bir yapıya kavuşan uluslararası sermaye akımları ve gelişen teknoloji sayesinde günümüzde uluslararası portföy yatırımları oldukça büyük boyutlara ulaşmıştır. Bu durumun doğal bir neticesi olarak uluslararası piyasalar tarihin hiçbir döneminde olmadiğg kadar entegre bir hale gelmişlerdir. Artık bir piyasada meydana gelen bir dalgalanma sadece kendi ülke piyasalarını etkilemekle kalmayıp, uluslararası piyasalarda da dalgalanmalara neden olmaktadır. Piyasalarda artan uluslararası entegrasyon ise uluslararası çeşitlendirmenin faydalarını kısıtlayan bir olgudur. Uluslararası piyasalarda artan entegrasyon neticesinde, akademik literatürde optimal ürün ve pazarların saptanmasına yönelik araştırmalar yapılmaktadır (Ataş, 2019:76). Günümüzde 
gelişmiş ülkelerden gelişmekte olan ülkelere doğru veya tam tersi meydana gelen sermaye akımları söz konusudur. Bu sayede daha optimize portföyler oluşturulabilmektedir (Gilmore, McManus, 2002:70-71).

Modern portföy teorisi ile ilgili literatürün önemli bir kısmı da çeşitlendirme ve bunun özel bir türü olan uluslararası çeşitlendirmeye ayrılmıştır. Yapılan ampirik araştırmalar yolu ile hangi piyasaların ve hangi ürünlerin en iyi çeşitlendirme faydasını sağladığı saptanmaya çalışılmaktadır. Birçok çalışmada uluslararası varlıkların yurtiçi varlıklara göre daha düşük korelasyon gösterdikleri bu nedenle daha gelişmiş bir çeşitlendirme imkanı sağladıkları görülmüştür. (Solnik, 1974:52), (Driessen ve Laeven, 2007:1694), (Lessard, 1976:33) Gelişmiş ülke piyasalarında yapmış oldukları çalışmalarda uluslararası varlık yatırımlarının sadece yurtiçi yatırımlarına göre daha iyi optimize edilmiş portföyler meydana getirdiklerini göstermişlerdir.

Uluslararası çeşitlendirme araştırmalarının en çok yapıldığı alanlardan bir diğeri ise piyasaların bölgesel olarak diğer piyasalar açısından çeşitlendirme faydası ve risk minimizasyonu sağlayıp sağlamadığının araştırılmasıdır. (Cholette vd.,2011:416) G5 ülkeleri ve Asya ve Latin Amerika'nın da içinde bulunduğu 15 farklı ülkeyi kapsayan çalışmasında kopula bağımlılık analizini kullanmıştır. Çalışmanın sonuçlarına göre, G5 ile Latin Amerika ülkeleri arasında kısmen de olsa asimetrik bir bağımlılık varken, Asya ülkeleri ile bağımlılık tespit edilememiştir. (Becker vd., 1990:1305) Amerikan piyasası ve Japon piyasasını baz alarak yaptığı çalışmada Amerikan piyasasından Japon piyasasına doğru yayılan bir nedensellik söz konusu iken Japon piyasasından Amerikan piyasasına yayılan bir etki tespit edilememiştir. (Vo ve Daly, 2005:168) Avrupa Para birliği içerisindeki belli başl1 7 piyasa ve ABD finansal piyasaları arasındaki entegrasyonu araştırmıştır. Bulunan sonuçlar değişkenlik gösterse de Avrupa piyasaları ve ABD piyasası arasında özellikle uzun dönemde bir çeşitlendirme faydası olduğu söylenebilir. (Levy ve Lerman, 1988:63) dünya tahvil piyasası açısından çeşitlendirme faydasını araştırmış ve tahvil piyasaları açısından uluslararası çeşitlendirmenin faydasının sağlandığını tespit etmiştir. (You ve Daigler, 2010:172) Zamanla korelasyonun değiştiği durumlarda çeşitlendirme ilişkisini araştırmış, ve çeşitlendirmenin varlıklar arasındaki korelasyonun değişiminden etkilendiği sonucu elde edilmiştir. (Meriç ve Meriç, 1989:636) yaptıkları çalışmada seriler arası entegrasyonun uzun dönemde kısa döneme göre daha yoğun olduğunu tespit etmiştir. Başka bir deyişle uzun dönem seriler ve aynı serilere ait alt dönemler arasında farklı sonuçlar ortaya çıkabilmektedir.

Uluslararası çeşitlendirmenin önündeki en büyük sorun yatırımcıların uluslararası varlıkların daha iyi bir risk-getiri profili vadetmesine rağmen yerel varlıklara yatırım yaparken kendilerini daha konforlu hissetmesinden dolayı uluslararası yatırımlara mesafeli kalmasıdır. $\mathrm{Bu}$ duruma finans literatüründe yerel iltimas (home bias) denilmektedir. Bireysel yatırımcıların yurtiçi varlıkları daha çok benimsemesi nedeniyle yurtiçindeki bazı araştırmacılar sadece yurtiçinde uluslararası nitelik gösteren bazı varlıkları kullanarak uluslararası çeşitlendirme faydasının sağlanıp sağlanamadığını araştırmışlardır. (Errunza vd.,1999:2014) yapmış oldukları çalışmada yerel varlıkların uluslararası endekslere benzer hareket gösterip göstermediğini araştırmıştır. Çalışmanın sonucuna göre yerel yatırımcıların uluslararası endeksleri taklit edebilecekleri görülmüştür. Aynı şekilde (Lu ve Vivian, 2019:25) çalışması da yerel varlıklarla uluslararası endekslerin kısmen de olsa taklit edilebileceklerini göstermiştir. 


\section{VERİ VE METODOLOJI}

Çalışmamızda kira sertifikası varlığının diğer ulusal ve uluslararası hisse senedi ve tahvil gibi konvansiyonel varlıklarla uzun ve kısa dönemli ilişkisi incelenecektir. Uzun dönemli ilişkinin tespiti için (Johansen, 1988) koentegrasyon yöntemi kullanılacaktır. Uzun dönemli ilişki portföy yatırımları açısından da önem arz etmektedir. Ĕger iki varlık serisi veya seri grupları uzun dönemde dengeye gelerek beraber hareket ediyorlarsa bu varlıklar portföy çeşitlendirme optimizasyonu için uygun varlıklar değillerdir. $\mathrm{Bu}$ nedenle çalışmada elde edilen bulgular kira sertifikalarının konvansiyonel varlıklar açısından çeşitlendirme faydası sağlayıp sağlamadığı hakkında yorum yapmamıza olanak sağlayacaktır. Aşağıda tabloda çalışmada kullanılan veri setleri ve kapsadığı dönem verilmiştir.

Tablo 2. Çalışmada Kullanılan Veriler

\begin{tabular}{|l|l|l|}
\hline Endeks Kodu & Endeks Adı & Kapsadı̆̆ı Dönem \\
\hline \hline KYDKSKAMU & KYD Devlet Kira Sertifikası Endeksi & 2013 Haziran - 2019 Mayıs \\
KYDBTUM & KYD Devlet Tahvil Endeksi & 2013 Haziran - 2019 Mayıs \\
GXU100 & BIST 100 Getiri Endeksi & 2013 Haziran - 2019 Mayıs \\
FTSEBINDEX & FTSE Dünya Devlet Tahvil Endeksi & 2013 Haziran - 2019 Mayıs \\
ISTOXX1800 & STOXX 1800 Global Hisse Senedi Endeksi & 2013 Haziran - 2019 Mayıs \\
\hline \hline
\end{tabular}

Tüm veri setleri 2013 Haziran-2019 Mayıs arası dönemi kapsamaktadır. KYD Devlet Kira Sertifikası Endeksi, KYD Devlet Tahvil Endeksi ve BIST100 Getiri endeksi Finnet veri tabanından alınmıştır. FTSE Dünya Devlet Tahvili Endeksi ve STOXX 1800 Dünya Hisse Senedi Endeksi Bloomberg veri terminalinden temin edilmiştir. Hem ulusal hem de uluslararası endeksler baz alınarak kira sertifikaları ve bu endeksler arasındaki uzun ve kısa dönemli ilişski ölçülmek istenmiştir. Çalışmada aylık veriler kullanılmıştır. Aylık verilerin kullanılmasının sebebi kısa dönemli gürültü (noise trade) dalgalanmalarının çalışmanın sonuçlarına yapacağı olumsuz etkinin önüne geçmektir.

Johansen koentegrasyon yöntemi (Johansen, 1988), koentegrasyon kavramının ilk olarak (Engle, Granger, 1987) geliştirilmesinden kısa bir süre sonra, Engle-Granger’daki EKK tahminleyicisinin yerine maksimum olabilirlik tahminleyicisi kullanan ve bu yönüyle aynı sistem içerisinde birden fazla eşbütünleşik vektör ve ikiden fazla değişkenin olmasına olanak sağlayan ve bu yönüyle Engle-Granger iki aşamalı yönteminden daha gelişmiş bir model olduğu öngörülen bir istatistiksel tekniktir. Johansen koentegrasyon yöntemi klasik regresyon sistemine dayanmamaktadır. Bunun yerine serilerin farklı gecikme uzunluğundaki değişkenlerinin de aynı sistem içerisinde olmasına olanak sağlayan VAR (vektör otoregresif) modeline dayanmaktadır (Alexander, 2001:317).

$$
\Delta X_{t}=\mu+\sum_{i=1}^{n} \tau X_{t-i}+\alpha \beta^{\cdot} X_{t-i}+\varepsilon_{t}
$$

Yukarıda Johansen temel eşitliği verilmiştir. $X_{t}$, durağan olmayan tüm değişkenler için $n \times 1$ vektör olmak üzere, $\tau ;(n \times n)$ matriksidir. Johansen parametrelerin anlamlılığının 
testi için 2 farklı test geliştirmiştir. Bunlardan biri iz istatistiği iken diğeri maksimum öz değer istatistiğidir (Brooks, 2014:376).

Uzun dönemli ilişkinin yanında endeksler arasındaki kısa dönemli ilişki de varyans ayrıştırma analizi ile ölçümlenmiştir. Varyans ayrıştırma analizi aslında VAR otoregresif sisteminden türetilen bir analizdir. Fakat VAR modelinin modeldeki parametrelerinin yorumlanması oldukça güçtür. $\mathrm{Bu}$ nedenle VAR modelinden elde edilen parametrelerin yorumlanması için varyans ayrıştırma analizi yapılmaktadır. Varyans ayrıştırma analizi özünde, VAR sistemi içerisinde bir değişkende meydana gelen bir volatilitenin diğer değişken üzerindeki volatiliteyi yüzdesel olarak ne kadar açıkladığını gösteren bir yöntemdir. 5 farklı değişken bulunan ve 1 gecikme uzunluğuna sahip var sistemi denklemleri aşağıdaki gibi kurgulanacaktır. Bunun sonucunda kısa dönemde, hem kira sertifikasındaki değişimlerin diğer endeksler üzerinde meydana getirdiği etki hem de diğer değişkenlerde meydana gelen volatilitenin kira sertifikası endeksi üzerinde meydana getirdiği etki bulunacaktır.

$$
\begin{aligned}
& X 1_{t}=C_{1}+\alpha_{11} X 1_{t-1}+\alpha_{12} X 2_{t-1}+\alpha_{13} X 3_{t-1}+\alpha_{14} X 4_{t-1}+\alpha_{15} X 5_{t-1}+\epsilon_{1 t} \\
& X 2_{t}=C_{2}+\alpha_{21} X 1_{t-1}+\alpha_{22} X 2_{t-1}+\alpha_{23} X 3_{t-1}+\alpha_{24} X 4_{t-1}+\alpha_{25} X 5_{t-1}+\epsilon_{2 t} \\
& X 3_{t}=C_{3}+\alpha_{31} X 1_{t-1}+\alpha_{32} X 2_{t-1}+\alpha_{33} X 3_{t-1}+\alpha_{34} X 4_{t-1}+\alpha_{35} X 5_{t-1}+\epsilon_{3 t} \\
& X 4_{t}=c_{4}+\alpha_{41} X 1_{t-1}+\alpha_{42} X 2_{t-1}+\alpha_{43} X 3_{t-1}+\alpha_{44} X 4_{t-1}+\alpha_{45} X 5_{t-1}+\epsilon_{4 t} \\
& X 5_{t}=c_{5}+\alpha_{51} X 1_{t-1}+\alpha_{52} X 2_{t-1}+\alpha_{53} X 3_{t-1}+\alpha_{54} X 4_{t-1}+\alpha_{55} X 5_{t-1}+\epsilon_{5 t}
\end{aligned}
$$

Yukarıda 1 gecikmeli ve 5 değişkenli VAR sistemi verilmiştir. $X 1, X 2, X 3, X 4, X 5$ çalışmada baz alınan 5 farklı endeksi temsil etmektedir. $\alpha$ değerleri ise çalışmadaki parametrelerin katsayılarını göstermektedir. Bu model kurularak varyans ayrıştırma analizi ile kısa dönemde endeksler arası etkileşim ölçülecektir.

\section{SONUÇLAR}

Çalışmada ilk olarak uzun dönemli ilişkinin varlığının tespiti için koentegrasyon analizi yapılmıştır. Eğer KYD Türkiye Kira Sertifikası Endeksi ile diğer endeksler arasında uzun dönemli ilişki tespit edilirse bu endeks varlıklarının uzun dönemde benzer şekilde hareket ettikleri ve çeşitlendirme faydasının uzun dönem için sınırlı olacağı sonucunu söylemek mümkündür. Tersi durumda kira sertifikaları endeksinin çeşitlendirme açısından uygun bir varlık olduğu sonucuna ulaşılacaktır. Johansen Koentegrasyon Analizinin uygulanabilmesi için tüm serilerin aynı mertebeden durağan olması gerekmektedir. Aksi takdirde bu yöntem uzun dönemli ilişkinin tespiti için uygulanamaz. Çalışmada serilerin durağanlığını ölçmek amacıyla Augmented Dickey Fuller (ADF) yöntemi kullanılmıştır. Durağanlık testinin sonuçları aşağıda verilmiştir. 
Tablo 3. Serilerin Durağanlığı

\begin{tabular}{|c|c|c|c|c|}
\hline \multirow[b]{2}{*}{ Endeks } & \multicolumn{2}{|c|}{ Farkı Alınmadan } & \multicolumn{2}{|c|}{ 1. Fark Dură̆anlık } \\
\hline & $\begin{array}{c}A D F(t) \text { Istatistiği } \\
\text { Değeri }\end{array}$ & Olasılık Değgeri & $\begin{array}{c}A D F(t) \text { Istatistiğ } i \\
\text { Değgeri }\end{array}$ & Olasılık Dĕğeri \\
\hline KYDKSKAMU & 0.207943 & 0.9709 & -5.655 .826 & $0.0000 *$ \\
\hline KYDBTUM & -1.155 .940 & 0.6876 & -7.480 .272 & $0.0000 *$ \\
\hline GXU100 & -0.764239 & 0.8216 & -6.917 .152 & $0.0000^{*}$ \\
\hline FTSEBINDEX & -1.813 .563 & 0.3705 & -6.315 .707 & $0.0000 *$ \\
\hline ISTOXX1800 & -1.327 .272 & 0.6113 & -6.528 .933 & $0.0000 *$ \\
\hline
\end{tabular}

*\%5 seviyesinde durağan

Yukarıdaki tabloda çalışmada kullanılan tüm serilerin ham halleriyle durağan olmadıkları, her birisinin birinci farkını aldıktan sonra durağan hale geldikleri görülmektedir. $\mathrm{Bu}$ haliyle analizimizde yer alan 5 farklı endeks serisi koentegrasyon analizi için uygun serilerdir. Çalışmanın bir sonraki ayağında Johansen koentegrasyon testi uygulanmıştır. Bulunan sonuçlar aşağıdaki tabloda verilmiştir.

Tablo 4. Johansen Koentegrasyon Testi Sonuçları

\begin{tabular}{|cccc|}
\hline Koentegre Vektör & İz İstatistiği & \%5 Kritik Değer & Olasılık Değeri* \\
\hline Hiç & 4.812 .648 & 6.981 .889 & 0.7167 \\
En Çok 1 & 2.341 .420 & 4.785 .613 & 0.9540 \\
En Çok 2 & 1.031 .045 & 2.979 .707 & 0.9754 \\
En Çok 3 & 2.879 .652 & 1.549 .471 & 0.9721 \\
En Çok 4 & 0.193851 & 3.841 .466 & 0.6597 \\
\hline Koentegre Vektör & Maksimum Öz Değer İstatistiği & \%5 Kritik Değer & Olasılık Değeri* \\
\hline Hiç & 2.471 .228 & 3.387 .687 & 0.4047 \\
En Çok 1 & 1.310 .375 & 2.758 .434 & 0.8791 \\
En Çok 2 & 7.430 .801 & 2.113 .162 & 0.9350 \\
En Çok 3 & 2.685 .801 & 1.426 .460 & 0.9654 \\
En Çok 4 & 0.193851 & 3.841 .466 & 0.6597 \\
\hline
\end{tabular}

Koentegrasyon analizi için hem iz istatistiği hem de maksimum öz değer istatistiği sonuçlarına bakılmıştır. Koentegrasyon analizinde en önemli girdilerden biri ise otoregresif sistem içerisinde kaçıncı gecikme uzunluğunun kullanılması gerektiğidir. Bunun cevabını bulmak için Akaike Bilgi Kriteri ve Schwarz Bilgi Kriteri baz alınmıştır. Hem Akaike hem de Schwarz Bilgi Kriterine göre 1. gecikmenin sistem içerisinde en uygun gecikme uzunluğu olduğu görülmüsstür. Tablodaki verilerden $\% 5$ anlamlılık seviyesinde 5 farklı endeks serisi arasında hiç anlamlı koentegre vektörün bulunmadığı görülmektedir. Buna göre Devlet Kira Sertifikası Endeksi ile diğer seriler arasında uzun dönemli ilişki bulunmamaktadır. Başka bir deyişle, uzun dönemde, bahsi geçen 5 farklı seri dengeye gelerek beraber hareket etmemektedir. $\mathrm{Bu}$ durumda, uzun dönemde Türkiye Kira Sertifikalarının çeşitlendirme açısından kullanımı; uluslararası tahvil ve hisse senedi portföyü açısından faydalı olacağ gibi, ulusal tahvil ve hisse senedi portföyü açısından da faydalı bir alternatif olacaktır. Ulusal 
ve uluslararası konvansiyonel piyasa yatırımcıları, uzun dönemde, Türkiye Hazine Müsteşarlığı tarafından ihraç edilen kira sertifikalarını kullanarak mevcut portföylerinin risklerini daha da minimize edebilirler.

Koentegrasyon analizi uzun dönemli ilişkinin varlığını tespit etmek açısından kullanımı uygun ve yerinde olmasına rağmen bu yöntem, seriler arasındaki kısa dönemli ilişki açısından herhangi bir bilgi vermemektedir. Çalışmamızın bir sonraki ayağında Vector Autoregressive (VAR) modeli kullanılarak seriler arasında kısa dönemli ilişki incelenecektir. VAR analizinin kullanılabilmesi için kullanılan zaman serilerinin durağan hale getirilmesi gerekmektedir. Bunun için tüm serilerin birinci farkları alınmıştır. Kurulan VAR modeli neticesinde diğer 4 farklı seri ve KYD Kira Sertifikası Endeksi arasında kısa dönemli ilişki varyans ayrıştırma yöntemi ile analiz edilmiştir.

Tablo 5. Varyans Ayrıştırma Testi Sonuçları

\begin{tabular}{|l|ccccc|}
\hline \multicolumn{1}{c|}{$\%$} & KYDKSKAMU & KYDBTUM & GXU100 & FTSEBINDEX & ISTOXX1800 \\
\hline KYDKSKAMU & 58,9 & 34,6 & 0,4 & 6,1 & 0,0 \\
KYDBTUM & 0,0 & 81,4 & 0,0 & 12,8 & 5,8 \\
GXU100 & 0,0 & 22,5 & 60,6 & 13,6 & 3,3 \\
FTSEBINDEX & 0,0 & 0,0 & 0,0 & 100,0 & 0,0 \\
ISTOXX1800 & 0,0 & 0,0 & 0,0 & 14,3 & 85,7 \\
\hline
\end{tabular}

Varyans ayrıştırma analizi VAR otoregresif sistemi içerisinde yer alan parametrelerin bir dönemde meydana gelen değişimlerinin kaynağının belirlenmesi amacıyla kullanılmaktadır. Başka bir ifadeyle varyans ayrıştırma analizi VAR modelinde bir değişkende meydana gelen değişimlerin modeldeki diğer değişkenler üzerindeki etkisini yüzdesel olarak ifade etmektedir. Yukarıdaki tabloda VAR sistemi içerisindeki parametrelerin bir dönem sonunda meydana gelen değişimlerinin kaynakları yüzdesel olarak verilmiştir. Kısa dönemli etki ölçülmek istendiği için sadece bir dönemlik değişime bakılmıştır. Buna göre Kira sertifikaları Endeksinde kısa dönemde meydana gelen bir değişim, \%58,9 kendi iç şoklarından kaynaklanmaktayken, \%34,6 Türkiye Devlet Tahvili Endeksinden, \%6,1 de Dünya Devlet Tahvili Endeksinden kaynaklanmaktadır. Türkiye ve Dünya hisse senetleri endeksindeki değişimlerin Türkiye Kira Sertifikaları Endeksi üzerine etkilerinin oldukça sınırlı seviyede olduğu görülmektedir. Diğer taraftan Kira Sertifikaları Endeksinde meydana gelen değişimler Türkiye ve Dünya Tahvil piyasalarında meydana gelen değişimler tarafindan açıklanabilirken Kira Sertifikaları Endeksinin hem Türkiye hem de Dünya Tahvil endeksi üzerinde etkisi bulunmamaktadır. Bu nedenle etkileşimin diğer varlıklardan Kira Sertifikası varlıklarına doğru tek taraflı olarak (one sided) gerçekleştiği anlaşılmaktadır. Kira sertifikaları piyasa büyüklügü bakımından konvansiyonel tahvil piyasalarından oldukça küçük olduğu için bulunan bu sonuç aslında beklenen bir durumdur. Kira sertifikaları piyasasında meydana gelen varyans kısa dönemde büyük bir oranda ulusal tahvil piyasasında meydana gelen değişimlerle açıklanabilirken aynı zamanda uluslararası tahvil piyasasından da etkilenmektedir. Diğer taraftan kira sertifikası piyasasında yaşanan dalgalanmaların ne ulusal ne de uluslararası piyasalarda bir geçişkenlik yaratmadığı tablodan anlaşılmaktadır. 


\section{GENEL DEĞERLENDİRME}

Günümüz sermaye piyasalarında oldukça farklı türlerde menkul kıymetler alınıp satılmaktadır. Şüphesiz sermaye piyasalarındaki ürün çeşitliliğinin artması hem piyasa derinliğinin artırılması hem de atıl kalan fonların piyasaya kazandırılması noktasında önem arz etmektedir. Kira sertifikaları da bu bağlamda sermaye piyasalarına yeni kazandırılmış bir menkul kıymet türüdür. Türkiye kira sertifikaları piyasası hazine müsteşarlığı ve katılım bankalarının ihraç etmiş olduğu kira sertifikalarının işlem gördüğü bir piyasa olmakla birlikte günümüzde piyasa büyüklüğü ve bilinirliği açısından önemi giderek artmaktadır. Çalışmanın temel amacı piyasa büyüklüğü ve bilinirliği günden güne artan bu yeni enstrümanın piyasada zaten var olan konvansiyonel hisse senedi ve tahvil yatırımcıları açısından da yatırım yapılabilir bir araç olup olmadığının analizinin yapılmasıdır. Bu nedenle kira sertifikaları piyasalarının ulusal ve uluslararası yatırımcılar açısından bir çeşitlendirme faydası sağlayıp sağlamadığı çalışmanın temel sorusu olmuştur.

Çalışmada Türkiye sermaye piyasalarındaki yeni bir ürün olan kira sertifikaları ulusal ve uluslararası çeşitlendirmeye katkısı incelenmiştir. $\mathrm{Bu}$ amaçla serilerin uzun dönemde beraber hareketliliğini ölçebilmek amacıyla Johansen koentegrasyon yöntemi kullanılmıştır. Ulusal konvansiyonel yatırım araçlarını temsilen ulusal hisse senedi ve tahvil endeksleri ve uluslararası konvansiyonel yatırım araçlarını temsilen de uluslararası hisse senedi ve tahvil endeksleri kullanılmıştır. Çalışmada istatistiksel olarak, kira sertifikaları endeksinin hem ulusal hisse senedi ve tahvil endeksi hem de uluslararası hisse senedi ve tahvil endeksleriyle uzun dönemli ilişkisinin olmadığı tespit edilmiştir. Başka bir deyişle, kira sertifikaları endeksi diğer ulusal ve uluslararası endekslerle uzun dönemde dengeye gelmeyip farklı fiyatlama davranışları sergilemektedir. Bu nedenle kira sertifikalarını risk minimizasyonu için ulusal ve uluslararası portföylere dahil etmek risk minimizasyonu noktasında istatistiksel olarak olumlu sonuçlar vermektedir. Bu piyasaların diğer ulusal ve uluslararası piyasalarla entegre olmaması, bu piyasanın henüz bir bebek piyasa olması dolayısıyla tam olarak ikincil piyasasının ve piyasa derinliğinin tam oluşmaması gibi nedenlerle piyasadaki dalgalanmalara dinamik bir şekilde reaksiyon göstermemesi olarak açıklanabilir. Ayrıca kira sertifikaları islami kurallara göre düzenlenmiş ve dini duyarlılıkları yüksek yatırımcı grupları tarafından tercih edilen bir yatırım aracıdır. $\mathrm{Bu}$ nedenle kira sertifikalarının yatırımcilarının konvansiyonel piyasa yatırımcılarından farklı piyasa davranışları sergilemeleri piyasalar arasındaki ayrışmanın bir başka nedeni olarak düşünülebilir.

Çalışmada ayrıca varyans ayrıştırma yöntemi kullanılarak kısa dönemli ilişki de ölçülmüş̧ür. Bulunan sonuçlara göre kısa dönemde kira sertifikaları piyasası yoğun olarak kendi iç şoklarından etkilenmektedir. Bunun yanında kira sertifikalarındaki varyansın önemli bir kısmı da ulusal tahvil piyasasından kaynaklanırken ayrıca uluslararası tahvil piyasasının da etkili olduğu görülmüştür. Ayrıca hem ulusal hem de uluslararası hisse senedi piyasasının, kısa dönemde kira sertifikası piyasası varyansı üzerinde etkisi gayet küçük ve önemsiz düzeydedir. Diğer taraftan kira sertifikası piyasasının diğer ulusal ve uluslararası piyasalarda meydana gelen dalgalanmalar üzerinde etkisi bulunmamaktadır. Nitekim ölçek olarak kıyaslandığında diğer piyasalara göre oldukça küçük bir büyüklüğe sahip olmasından dolayı bu sonucun gerçekleştiği düşünülmektedir.

Sonuç olarak kira sertifikası yatırımı hem hisse senetleri portföyü hem de tahvil portföylerine çeşitlendirme noktasında olumlu katkı sağlamaktadır. Piyasada sınırlı bilgiye 
sahip ve yüksek komisyon oranları uygulanan bireysel yatırımcıların böyle kompleks bir endeks portföyü yatırımını gerçekleştirmesinin bir hayli zor olduğu söylenebilir. Fakat bireysel yatırımcılar da, yukarda bahsi geçen endeksleri baz alan yatırım fonlarını kullanarak kira sertifikalarının sağladığı çeşitlendirme faydasından kolaylıkla yararlanabilirler.

\section{KAYNAKLAR}

Alexander, Carol. (2001), Market Models: A Guide to Financial Data Analysis, Publisher: John Wiley \& Sons; Har/Cdr edition

Ataş, Berkan. (2019), Faizsiz Finansal Enstrümanlar Ve Konvansiyonel Enstrümanlarla Uzun Dönemli İlişkisinin İncelenmesi”, İstanbul Üniversitesi, Sosyal Bilimler Enstitüsü, Doktora Tezi.

Becker, G. Kent. - Finnerty, E. Joseph - Gupta, Manoj (1990), “The Intertemporal Relation Between The U.S. And Japanese Stock Markets”, The Journal of Finance , Sep., 1990, Vol. 45, No. 4 (Sep., 1990), pp. 1297-1306

Brooks, C. (2014) Introductory Econometrics For Finance, 3rd. Edition, Cambridge University Press

Chollete, Loran. - de la Peña, Victor - Lu, Ching-Chih. (2011 "International Diversification: A Copula Approach”, Journal of Banking and Finance, 35 (2), pp.403-417.

Driessen, Joost - Laeven, Luc. (2007), “International Portfolio Diversification Benefits: Cross-Country Evidence From A Local Perspective”, Journal of Banking \& Finance 31(6),pp. 1693-1712.

Engle Robert. F. - Granger C. W. J. (1987),“Co-Integration and Error Correction: Representation, Estimation, And Testing”, Econometrica, Vol. 55, No. 2, pp. 251-276.

Errunza, Vihang. - Hogan Ked - Hung, Mao-Wei. (1999). "Can The Gains From İnternational Diversification Be Achieved Without Trading Abroad?”, The Journal of Finance 54(6), pp. 2075-2107.

Gilmore, Claire G. - Mcmanus, Ginette M. (2001), "International Portfolio Diversification: US And Central European Equity Markets", Emerging Markets Review, 3(1),pp. 69$83 \cdot$

Greene, William H. (2018) Econometric Analysis, Pearson; 8 edition

IIFM (2019) “IIFM Sukuk Report” July 2019, 8th edition

Johansen, Soren. (1988), "Statistical Analysis of Cointegration Vectors", Journal of Economic Dynamics and Control, Volume 12, Issues 2-3, June-September 1988, pp. 231-254

Kellner, Ralf - Rösch Daniel. (2019), “A Country Specific Point of View on International Diversification”, Journal of International Money and Finance, Volume 98, pp. 102064 
Lessard, Donald R. (1976), “World, Country, and Industry Relationships in Equity Returns: Implications for Risk Reduction Through International Diversification”, Financial Analysts Journal,32(1) , pp. 32-38.

Levy, Haim. - Lerman, Zvi. (1988), "The Benefits of International Diversification in Bonds", Financial Analysts Journal, 44, pp. 56-64.

Lu, Qinye. - Vivian, Andrew. (2019), "Domestically Formed International Diversification" Journal of International Money and Finance, 2 December, pp.1-29.

Markowitz, Harry (1952), "Portfolio Selection", The Journal of Finance, 7(1) , pp. 77-91. https://doi.org/10.1111/j.1540-6261.1952.tb01525.x

Markowitz, Harry (1959), Portfolio Selection: Efficient Diversification of Investments, Yale University Press. Retrieved, http://www.jstor.org/stable/j.ctt1bh4c8h

Meriç, İlhan - Meriç, Gülser. (1989), "Potential Gains From International Portfolio Diversification And Inter-Temporal Stability And Seasonality in İnternational Stock Market Relationships", Journal of Banking \& Finance, 1989, vol. 13, issue 4-5, pp. 627-640

Moody’s (2019) “Global Sukuk Issuance to Rise For Fourth Year”, Research Announcement, August 27.

Okuyan, H. Aydın - Deniz, Devran. (2017), "Portföy Yönetiminde Uluslararası Çeşitlendirme Üzerine Uygulamalı Bir Çalışma”, Hacettepe Üniversitesi İktisadi ve İdari Bilimler Fakültesi Dergisi, Cilt 35, Sayı 2, ss. 71-92

Omet, Ghassan (1996), "The International Diversification of Investment Portfolios", Dirasat: Administrative Sciences 23(2) , pp. 185-191

O'Sullivan Niall. (2002), "Stocks and Bonds: Eggs in The Same or Different Baskets - A Cointegration Analysis", August 24, Available at http://dx.doi.org/10.2139/ssrn.2269553

Shawky, Hany A. - Kuenzel, Rolf. - Mikhail, Azmi D. (1997), "International Portfolio Diversification: A Synthesis And An Update", Journal of International Financial Markets, Institutions and Money 7(4) , pp. 303-327.

Solnik, Bruno H. (1974), "Why Not Diversify Internationally Rather Than Domestically?”,Financial Analysts Journal 30(4) , pp. 48-54.

Vo, Xuan. V. - Daly, Kevin. J. (2005) "European Equity Markets Integration-Implications for U.S. Investors”, Research in International Business and Finance, pp. 155-170

Yakar, Soner. - Kandır Serkan Y. - Önal Yıldırım B. (2013), "Yeni Bir Finansman Aracı Olarak (Sukuk-Kira Sertifikası) Ve Vergisel Boyutunun İncelenmesi”, Bankalar Birliği Dergisi, Sayı:24, pp. 72-95 
Yiğiter, Şule. Y. - Akkaynak, Bilal. (2017), "Modern Portföy Teorisi: Alternatif Yatırım Araçları İle Bir Uygulama”, KSÜ Sosyal Bilimler Dergisi Cilt: 14, Sayı: 2, pp. 285300

You, Leyuan. - Daigler, Robert. T. (2010), "Is International Diversification Really Beneficial?" Journal of Banking \& Finance, 2010, vol. 34, issue 1, pp. 163-173 